\title{
Principal Component ANALYSis AND MORPHOSTRUCTURAL CHARACTERIZATION OF a Portion of The Eastern Continental Shelf of Ceará, Brazil, Using LANDSAT 5-TM IMAGES
}

\section{Cynthia Romariz Duarte ${ }^{1 *}$, Elicius Feijó Cordeiro ${ }^{2}$, José Higor Batista Araujo Da Costa ${ }^{3}$, José ANTONio Beltrão Sabadia ${ }^{1}$, ANa Rita Salgueiro ${ }^{1}$, Michael Vandesteen Silva Souto ${ }^{1}$, Wellington FERREIRA DA SILVA FILHO ${ }^{1}$}

1 Departamento de Geologia - Universidade Federal do Ceará, Campus do Pici - Bloco 912, CEP 60440-554, Fortaleza, Ceará, Brazil, Tel: (85)3366-9867.cynthia.duarte@ufc.br, beltrao.sabadia@gmail.com, geo.ritasalgueiro@gmail.com, michael.souto@ufc.br, welfer@ufc.br.

2 Geoanálise - Engenharia em Geoprocessamento. R. Nunes Valente, 136 - Meireles, Fortaleza - CE, CEP 60125-070, Tel: (85) 3067-1199, elicius@gmail.com.

3 HB Consultoria. Rua Carlos Gondim, 14, s. 02, Fortaleza, Ceará, Brazil, CEP 60346-452. hig_182@hotmail.com.

*Corresponding Author, cynthia.duarte@ufc.br

Received on 29 Mars 2016

Received in revised form on 20 September 2016

Accepted on 24 September 2016

Editor:

Maria Virginia Alves Martins, Universidade do Estado do Rio de Janeiro, Brazil

\begin{abstract}
This study used Landsat 5 Thematic Mapper (5-TM) images in the morphostructural characterization of the shallow continental shelf of the eastern coast of Ceará (CE), in the Jaguaribe river mouth. The dam built near the river mouth to transpose the water towards Fortaleza, CE, ensures good water transparency since little of the river-carried sediment reaches the sea.
\end{abstract}

The used image was captured on date and time to ensure low tide. Data using Secchi disc indicated good water transparency in the turbidity zone and seaside, coastal and marine areas. Bathymetry studies and underwater photos confirm the existence of many of the features described in this study. Digital image processing techniques have been applied in the study: colored compositions (RGB 124), $90^{\circ}$ directional filter (band 1), and a colored composition employing the filtered band 1 and band 2 and 4 .

The filtered image of band 1 allowed recognizing different features when interpreted in detail scale. The principal component analysis (PCA) was used here, calculating eigenvalues and eigenvectors. When applied to bands 1 to 5
Citation:

Duarte, C.R., Cordeiro, E.F., Araujo da Costa, J.H.B., Sabadia, J.A.B., Salgueiro, A.R., Souto, M.V.S., Silva Filho, W.F., 2016. Principal component analysis and morphostructural characterization of a portion of the eastern continental shelf of Ceará, Brazil, using Landsat 5-TM images. Journal of Sedimentary Environments, $1(3): 324-333$.

and 7, PCA generated good results in PC2, whose correlation with the blue band was 0.85 (explained cumulative variance of more than 96\%). Applied to the visible bands, PCA produced very similar results in PC1, and the correlation between the blue band and PC1 was 0.86 (explained cumulative variance of $94 \%$ ).

These results show that band 1 is the main contributor in studies of submerged morphological features. Each process resulted in a new image, from which it was possible to produce the map of the area representing morphostructural characteristics.

The use of digitally processed satellite images in the visible region greatly improves the characterization and mapping of submerged features in places with shallow and good transparency waters.

Keywords: Remote Sensing, Image Processing, Landsat 5TM, Continental Shelf, Morphostructural Features. 


\section{Introduction}

The knowledge of the coastal and ocean environments is fundamental to study climate change; to understand the impact of sediment supply on estuaries, coastal and praial dynamics; to locate important mineral resources; to determine the appropriate sites to build ports or various underwater structures, among others. The continental shelf, the ocean area closest to the continent, contains valuable natural resources and, therefore, has great ecological, geological, economic and political importance (Monteiro \& Maia, 2010).

In this sense, the mapping of submerged features using satellite imagery is becoming an important tool for primary mapping and guiding future studies, especially because the method is cheap and effective.

Satellite images operating in the visible range of the electromagnetic spectrum (EM) have been used successfully to study submerged features since the light reflected by seafloor can be "seen from space" (recorded by the sensor) in transparent and clear water conditions (which is the case in the study area). The intensity, however, depends on the type of bottom and depth, thus making bathymetry and identification of different types of ocean bottom, viable applications for these sensors.

Bathymetric studies from optical remote sensing images must use the bands between 440 and $540 \mathrm{~nm}$ of the electromagnetic spectrum, particularly in regions of lower absorption (between 455 and $490 \mathrm{~nm}$ ) and greater penetration in the water column (between 490 and $505 \mathrm{~nm}$ ). The other wavelengths of the visible spectrum $(520-700 \mathrm{~nm})$ are significantly absorbed by the water column. The blue spectral band $(455-520 \mathrm{~nm})$ is used due to the water penetration ability. It allows viewing and identifying the submerged features since this area is free of organic and inorganic components, such as chlorophyll and sediments suspension, which cause scattering and absorption, preventing the bottom mapping (Epiphanio et al., 2009). Gao (2009) stated that bathymetry performed from the optical remote sensing, especially in the blue and green spectral range, is supported by the principle that the total amount of energy reflected from a water column is a function of water depth.

Vianna and Solewicz (1988) pioneered this type of satellite imagery application and concluded that orbital data can be widely used in underwater investigations to study the subsurface features even at depths greater than 10 meters. These authors also stated that these features may also be observed with clarity at the isobath of 30 meters. Testa and
Bosence (1999), Liu et al. (2003), Andréfouët and Riegl (2004), Gao (2009), Hamel and Andréfouët (2010), among others, demonstrated the potential of satellite imagery in bathymetric studies and recognition of underwater features, in the EM spectrum visible range.

In the northern coast of northeastern Brazil, Vianna et al. (1991), Tabosa and Vital (2006), Tabosa et al. (2007), Araújo and Amaral (2016) reported good results for data interpretation using optical satellite images and different techniques of digital image processing.

\section{Study area}

The Ceará coastal region extends approximately $570 \mathrm{~km}$, with E-SE and N-NW main directions. The Study Area is located in eastern Ceará (Fig. 1), approximately between $4^{\circ} 04^{\prime}$ and $4^{\circ} 30^{\prime} \mathrm{S}$ and $37^{\circ} 30^{\prime}$ and $37^{\circ} 50^{\prime} \mathrm{W}$, at the Jaguaribe river mouth, in Aracati, CE, Brazil.

According to Oliveira (2009) and Monteiro and Maia (2010) the identification of the submerged features through remote sensing may be impaired because a high turbidity zone forms the continental shelf in this region. In the Study Area, this range is estimated at about $5 \mathrm{~km}$ from the coastline. Secchi disc trials indicated depth of transparency between one and three meters (Monteiro, 2011). From this range, there is a coastal area between 5 and 15 meters deep, formed by sediments of marine and continental interface, where transparency is good despite the water depth. This effect results from the fact that the input of sediments from the Jaguaribe River are mainly transported from east to west, following the prevailing and active ocean currents in the area. Therefore, the remote sensing images of the coastal area allow identifying some of the most common submerged forms, such as sand waves and sand ridges, identified in situ by Monteiro (2011). In the intermediate zone (between 15 and 30 meters deep), there are algae banks, surrounded by unconsolidated sediments generated from the breakdown of calcareous algae and, from the 30-meter depth, sand ridges are observed perpendicular to the coast.

\section{Material and methods}

The image WRS 216/063 captured on September 1, 2009 used in this study was obtained by the Thematic Mapper sensor of the Landsat 5 satellite and download from the INPE website (National Institute for Space Research, Brazil; http://www.dgi.inpe.br/CDSR/). 


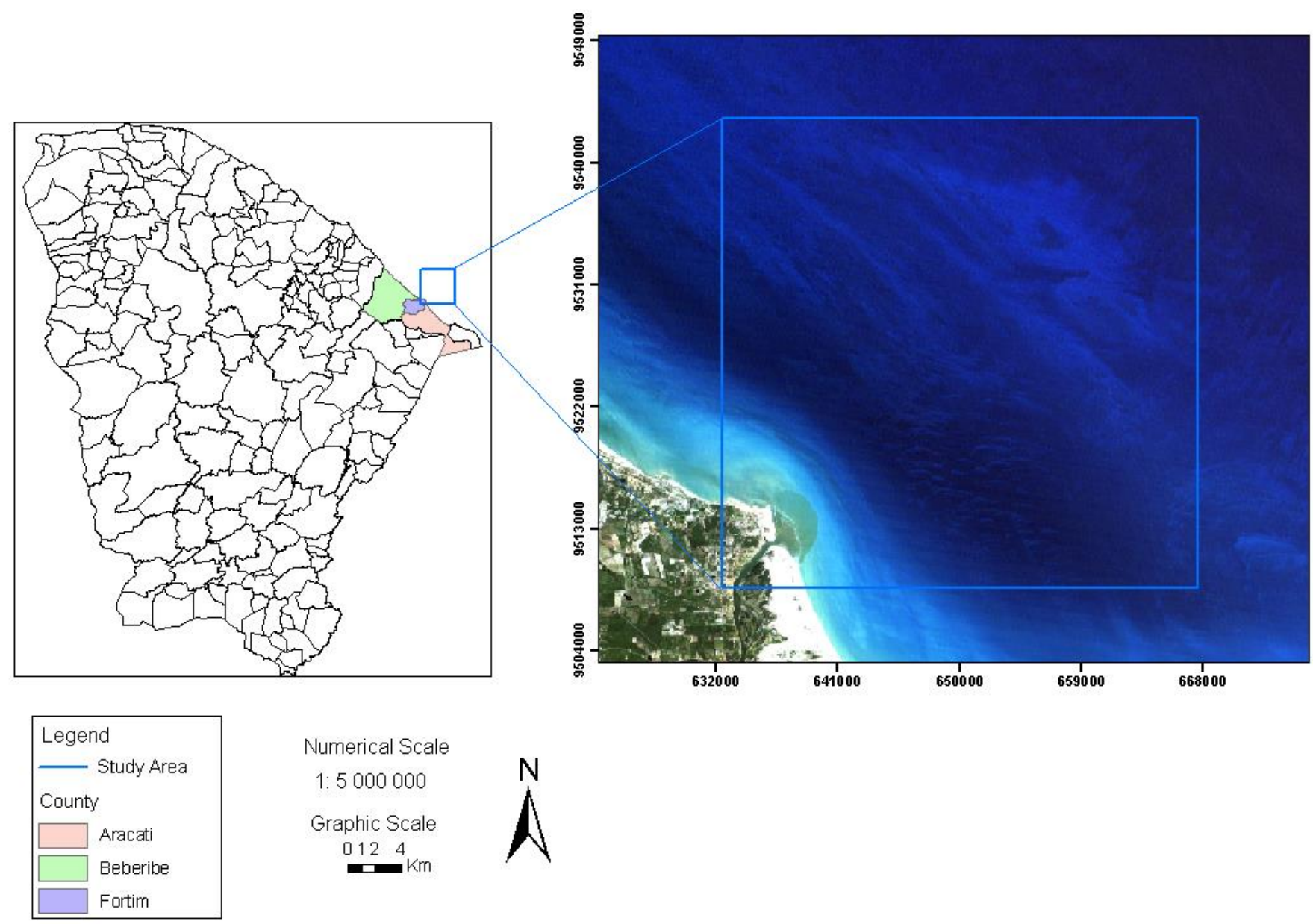

Fig. 1. Local of the Study Area (State of Ceará, Northeastern Brazil).

The studied image was acquired during low tide because the reduced thickness of the water depth optimizes the mapping of submerged structures. The Landsat 5 passing time is estimated at $10 \mathrm{~h}( \pm 15 \mathrm{~min})$ and at that time, the closest tide gauge indicated $0.75 \mathrm{~m}$ at $8 \mathrm{~h} 54$ min (mean between the two closest tide gauges, west and east of the area).

The image processing involved the pre-processing and digital processing steps to enhance the seafloor features. The preprocessing of the digital images is the initial processing of raw data for georeferencing the image, because the remote sensing images, such as raw satellite images are not precise and subject to geometric distortions, such as the Earth's rotation, changing altitude and satellite speed, among other factors. The whole image underwent the geocoding process to achieve the desired mapping accuracy, using the
GEOCOVER image, and migrating the data to UTM projection, datum WGS-84.

The electromagnetic energy reflected by the earth's surface is broken down and recorded in bands, through their interaction with the targets. This work employed the visible bands of the electromagnetic spectrum (EMS) to obtain images of submerged features in this region, due to the shorter wavelength and higher frequency of the electromagnetic radiation. The remote sensors operating in the visible region, such as Landsat 5-TM, are the best mapping tools in this type of research.

The processing of digital images is performed to increase the gain in the interpretation of remote sensing products. The processing steps used in this work sought to enhance the features and improve accuracy to facilitate the interpretation of results. We chose color compositions, 
contrast enhancements and directional filtering, and the principal component analysis as the statistical method.

The RGB colored compositions are used to enhance the subtle features of orbital images to help the data interpreter and analyzer since the human visual system is less sensitive to variations in shades of gray but quite sensitive to color variation.

The contrast enhancement discriminates better the targets in an image through a radiometric function $\mathrm{T}$, allowing the tonal variations within the original range of gray shades to be expanded, forcing the redistribution of data in all gray shades of the radiometry of the used remote sensing product, in this case, 8 bits. This redistribution greatly increases the distinctive character of the targets in a remote sensing image.

Another processing tool commonly used is the directional filters, which enhance the edges in a particular direction, combining the high pass filtering and grayscale threshold (Crosta, 1992). Attention is required when interpreting images subjected to this processing method since this filter can produce artificial edges, which may confuse data interpretation.

Frequently correlated, the information present in the spectral bands of an image provides redundant information, hampering the understanding and interpretation of the target image, thus making greatly difficult to analyze the spectral bands individually (Gonzalez \& Woods, 1992; Mather, 1999). Therefore, the principal components analysis (PCA) becomes an important tool since it applies a linear transformation of multispectral data to translate and rotate the data to a new coordinate system, thereby removing the correlation between the axes. This correlation arises from the shadow effect resulting from the topography, overlapping spectral bands between adjacent windows and own spectral behavior of objects, among other factors. Thus, the principal component analysis has the advantage of reducing the dimensionality of the data set by producing a new set of images whose individual bands contain information that is not present in other bands, allowing isolating the noise components generated by the satellites.

Chaves et al. (1991) noted that during the calculation process of the principal component, most of the information common to all multispectral bands is concentrated in the first principal component (PC1) and, therefore, this PC can assimilate the panchromatic information, while the spectral information exclusive of each band is allocated to the other principal components.

\section{Results and Discussion}

The products generated from the digital processing of the WRS 216/63 image from the Landsat 5-TM highlighted relevant morphostructural information, allowing detecting seafloor features (dunes, sand ridges, etc.) present on the submerged platform. The digital image processing was performed by the Envi 4.8 software.

Multispectral combinations were prepared using the spectral behavior of targets in the study area, and those that generated the best results were selected for subsequent interpretation. The main features of the seafloor in this area were highlighted by the RGB 321 composition, in the visible region of the EMS; the RGB 124 (Fig. 2) composition, together with the interpretation of the single-channel image of band 1 (Fig. 3); and the RGB composition formed by band 1 with applied directional filter, and bands 2 and 4 (Fig. 4).

The Principal Component Analysis (PCA) was performed on the six multispectral bands of this sensor system (excluding band 6, thermal region of EMS, from the process) to enhance the image. The PCA results are described in Table 1. The graphic projection of variables (bands) in the first factorial plane can be seen in Figure 5. It is noted that the two first factors (also called axes or PCs) explain about $97 \%$ of the total variance (Tab. 1) becoming, therefore, reasonable to assume that Figure 5 is a faithful representation of the six-dimensional space. The coordinates of the variables, and in this case the multispectral bands, may be taken as the correlation between the variables and the axes since the PCA algorithm applies a linear transformation to the covariance matrix of the original data set (Ongsomwang, 2007; Jolliffe, 2002; Jensen, 1986).

Table 1 shows each band of the correlated image with each of the PCA factors and independent from each other, which is expected taking into account the characteristics inherent to each band, and the fact that PCA reduced the image noise. Band 1 and PC2 are highly correlated, approximately 0.85 , the highest among the variable-factor correlations obtained.

Nevertheless, Figure 5 shows an alignment of bands along PC2, with band 1 strongly correlated with the positive semi-axis of the PC2 and the remaining bands successively aligned along PC2, except for bands 4 and 5 , which were more remote and more associated with PC1. 


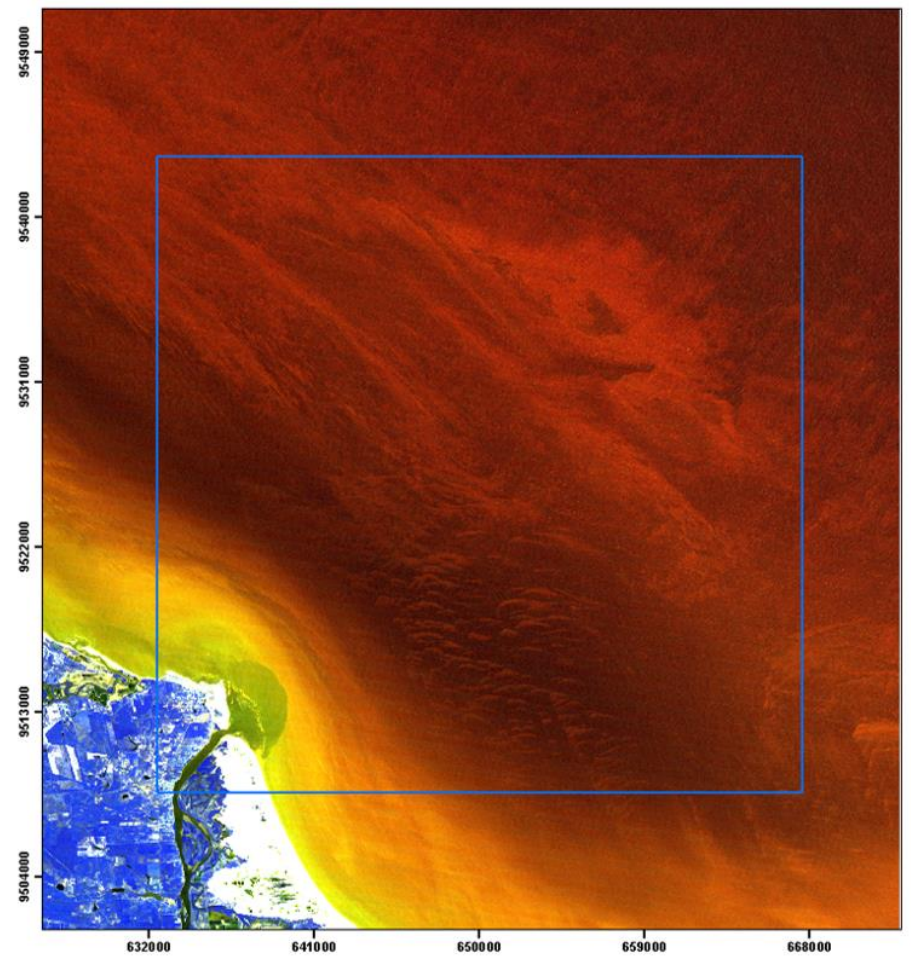

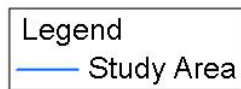

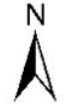

Graphic Scale

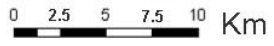

Fig. 2. False-color image (RGB 124) showing some of the morphostructural features of the region.
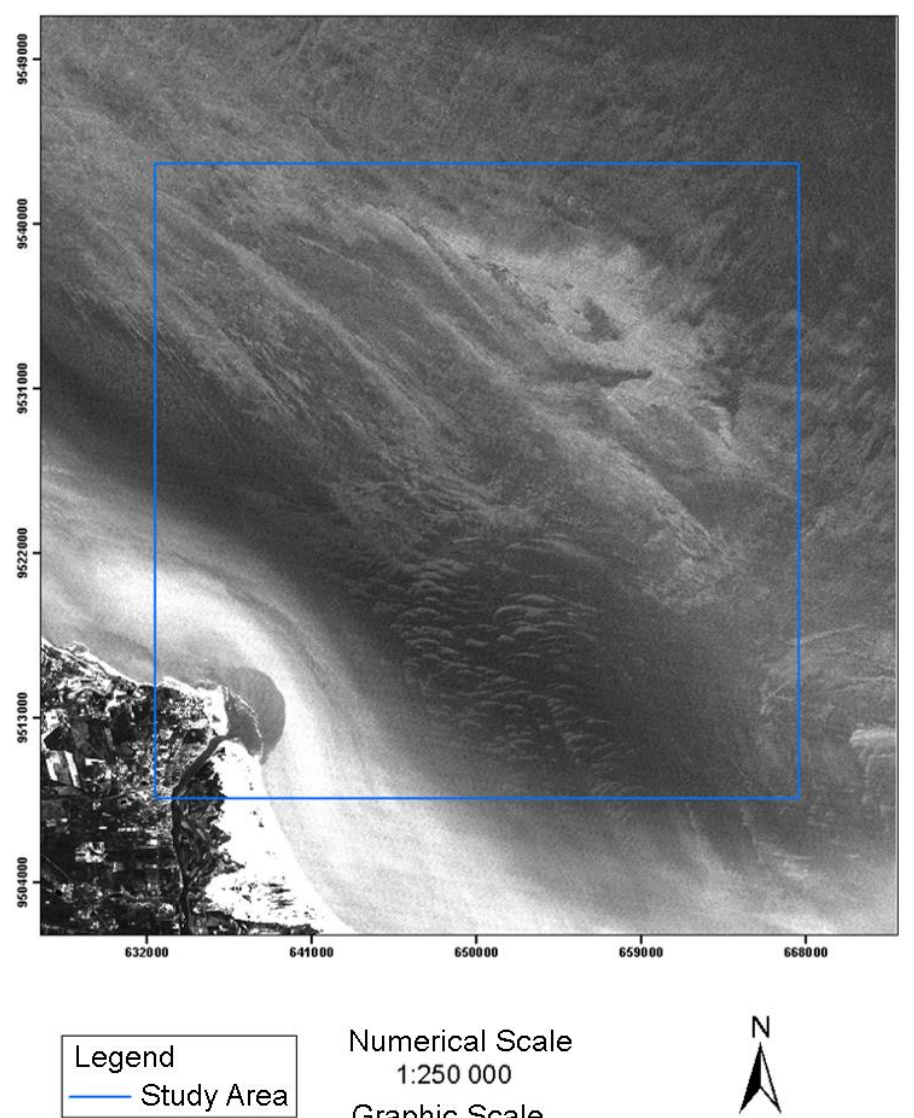

Numerical Scale 1:250 000

Graphic Scale

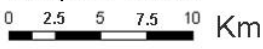

Fig. 3. Band 1 of the Landsat 5-TM image, highlighting the morphostructural features.

Tab. 1. Results of the eigenvectors and eigenvalues of the Principal Component Analysis (PCA) of the reflected multispectral bands of the image 216/63 captured on 09/01/2009.

\begin{tabular}{lcccccc}
\hline & PC 1 & PC 2 & PC 3 & PC 4 & PC 5 & PC 6 \\
\hline Band 1 & 0.3657 & 0.8476 & -0.0979 & 0.3112 & 0.1567 & -0.1301 \\
Band 2 & 0.1966 & 0.2469 & 0.0377 & -0.3460 & -0.4563 & 0.7556 \\
Band 3 & 0.2253 & 0.1438 & 0.2710 & -0.7064 & -0.1989 & -0.5627 \\
Band 4 & 0.4784 & -0.2420 & -0.7839 & -0.2479 & 0.1916 & -0.0042 \\
Band 5 & 0.6770 & -0.3630 & 0.3033 & 0.4296 & -0.3541 & -0.0898 \\
Band 7 & 0.2996 & -0.0981 & 0.4574 & -0.1962 & 0.7521 & 0.2956 \\
\hline Eigenvalue & 4502.579 & 921.047 & 162.255 & 31.841 & 5.500 & 1.987 \\
\hline Explained Variance (\%) & 80.00 & 16.37 & 2.88 & 0.57 & 0.10 & 0.03 \\
\hline Accumulated Explained & 80.00 & 96.37 & 99.25 & 99.82 & 99.92 & \multirow{2}{*}{99.95} \\
Variance (\%) & & & & & & \\
\hline
\end{tabular}




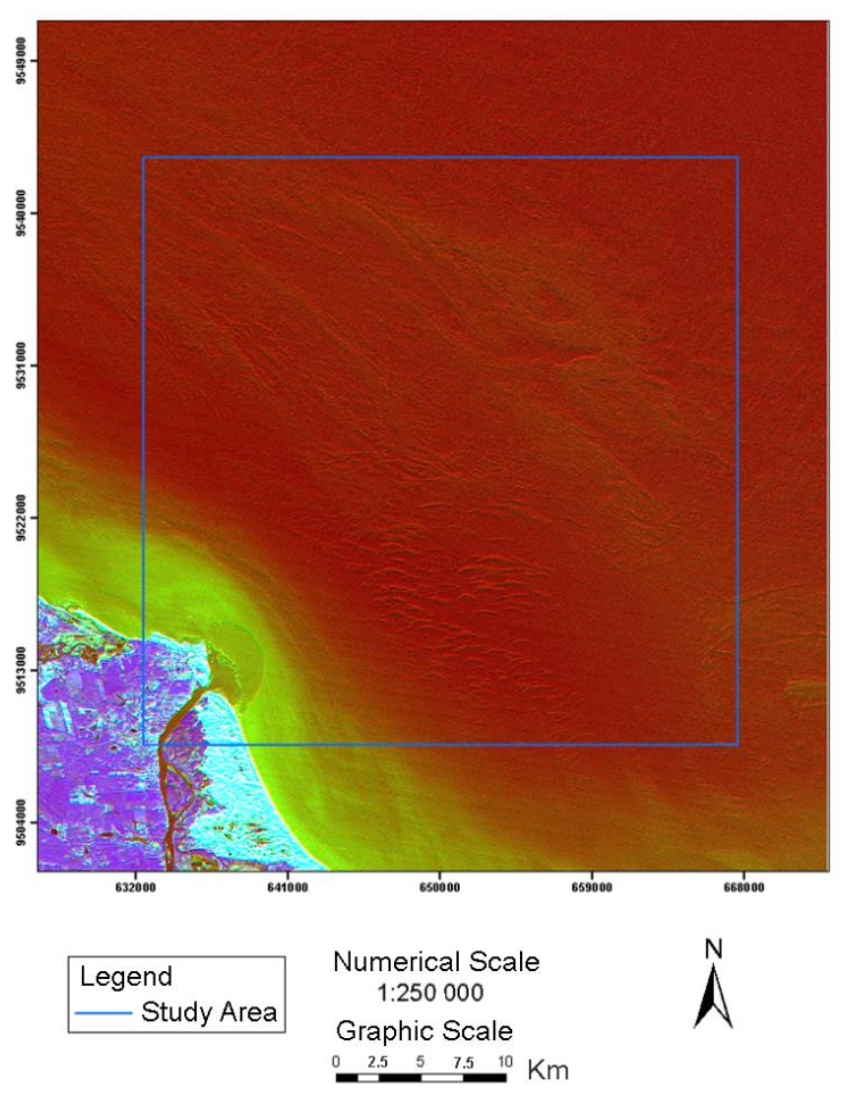

Fig. 4. RGB image made with band 1 , applying the $90^{\circ}$ directional filter (Fig. 3) and bands 2 and 4.

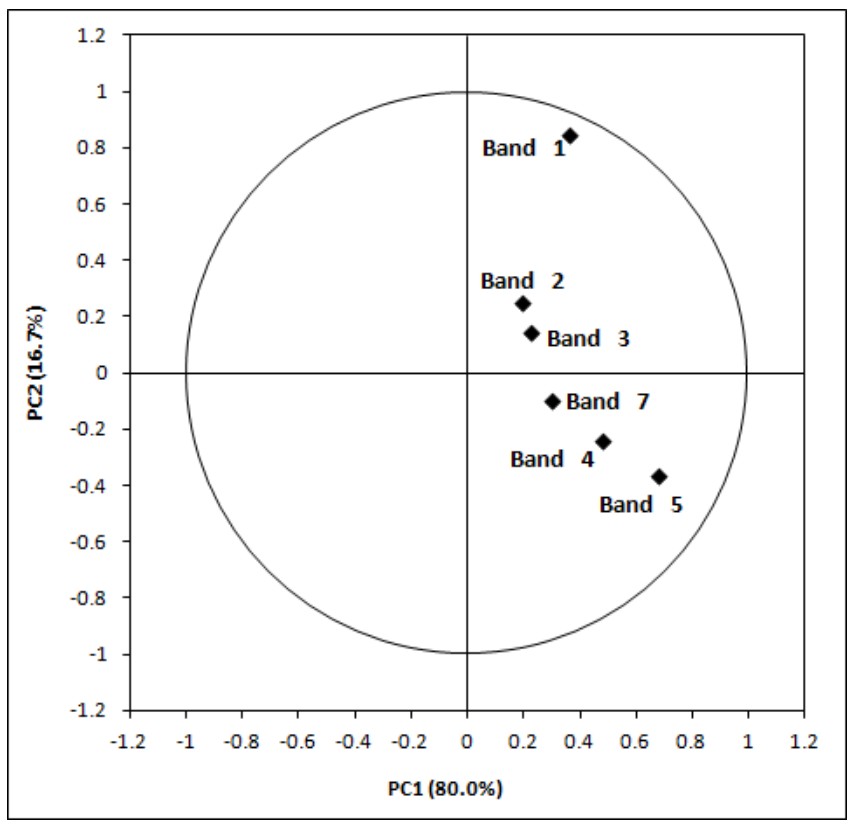

Fig. 5. Graph projection of the variables (bands) in the PCA factorial plane.
The Study Area is mostly a water body, and band 1 ( $\lambda$ Blue) of the TM sensor has the highest penetration in water bodies. Therefore, as expected the PCA results, which reflected the image transformed by PC2, showed the best results to identify the submerged features and minimized image noise (Fig. 6). The image obtained by PC1 was very similar to a panchromatic image (520-900 $\mathrm{nm})$, masking almost completely the submerged features.

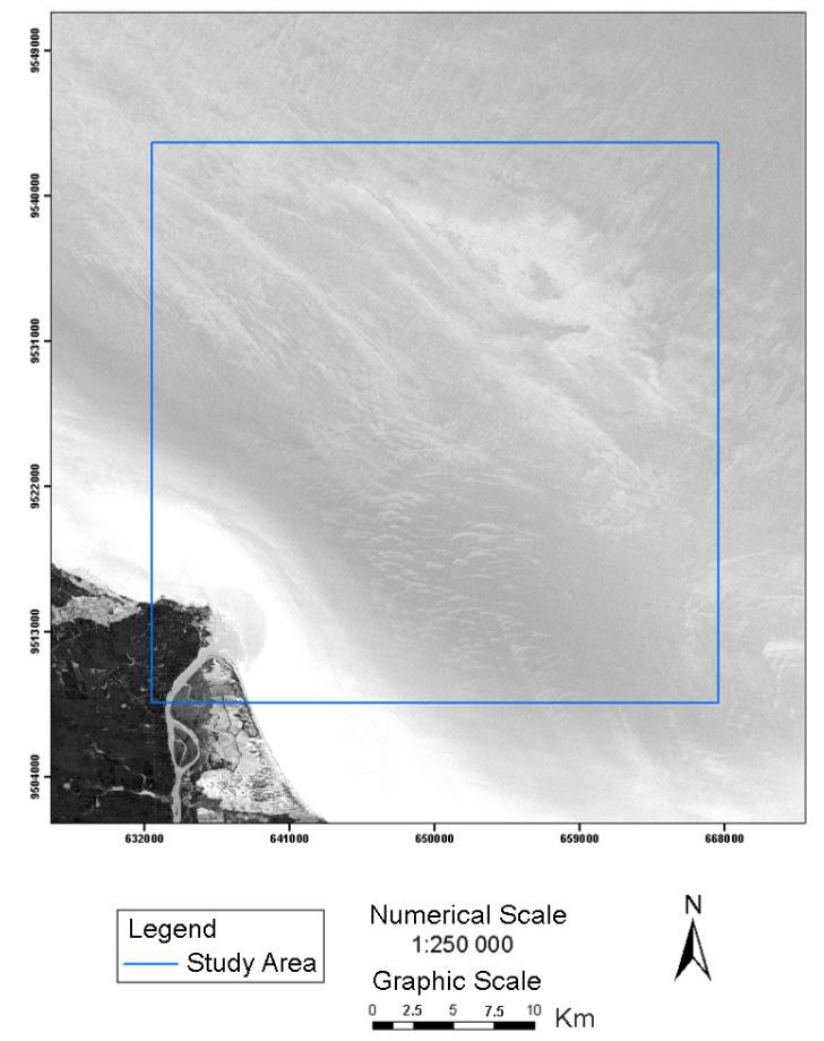

Fig. 6. Single-channel of PC2 of image 216/63, with seafloor morphological features evident in the coastal ( 5 to $15 \mathrm{~m}$ deep) and intermediate (15 to $30 \mathrm{~m}$ deep) areas.

Applying the PCA only to the visible bands of the image, the PC1 concentrated over $94 \%$ of the image variance (Tab. 2 ) showing a correlation of just over 0.86 , very close to the 0.85 correlation obtained between band 1 and PC2 using all multispectral bands (Tab. 1). Despite little or no reflectance of the EMS infrared region by water bodies, the results of eigenvectors and variance obtained using all reflected multispectral bands (bands 1 to 5 and 7 of Landsat TM) were satisfactory and similar to those using only the visible bands (bands 1 to 3). The EMS region where the water bodies have the best responses confirmed that even applied to all reflected bands of the TM sensor, the PCA presented satisfactory results. 
Tab. 2.:Eigenvector and eigenvalue results of the Principal Component Analysis of the visible bands of the image 216/63 captured on 09/01/2009.

\begin{tabular}{lccc}
\hline & PC 1 & PC 2 & PC 3 \\
\hline Band 1 & 0.8616 & 0.3648 & 0.3528 \\
Band 2 & 0.4730 & -0.3254 & -0.8188 \\
Band 3 & 0.1839 & -0.8724 & 0.4529 \\
\hline Eigenvalue & 1678.439 & 99.541 & 3.309 \\
\hline Explained variance (\%) & 94.22 & 5.57 & 0.18 \\
\hline Accumulated & 94.22 & 99.79 & 99.97 \\
Explained Variance (\%) & & &
\end{tabular}

The filtering technique was also used, and the $90^{\circ}$ directional filter was applied to band 1 ( $\lambda$ Blue). Regionally, the result did not appear suitable to identify underwater features, but it worked well to identify these features on the detail level, as shown in Figures 7 and 8.

The interpretation of several images generated from the above processing, as well as their integration, resulted in a map of the submerged features (Fig. 9) in the area of interest. The sand waves (dune fields) oblique to the coastline and the sand ridges, in addition to the sediment plume brought by the Jaguaribe River, are easily identified. The submerged dunes displayed E-W trend while the sand ridges had N-NW trend, generated by the actual currents.
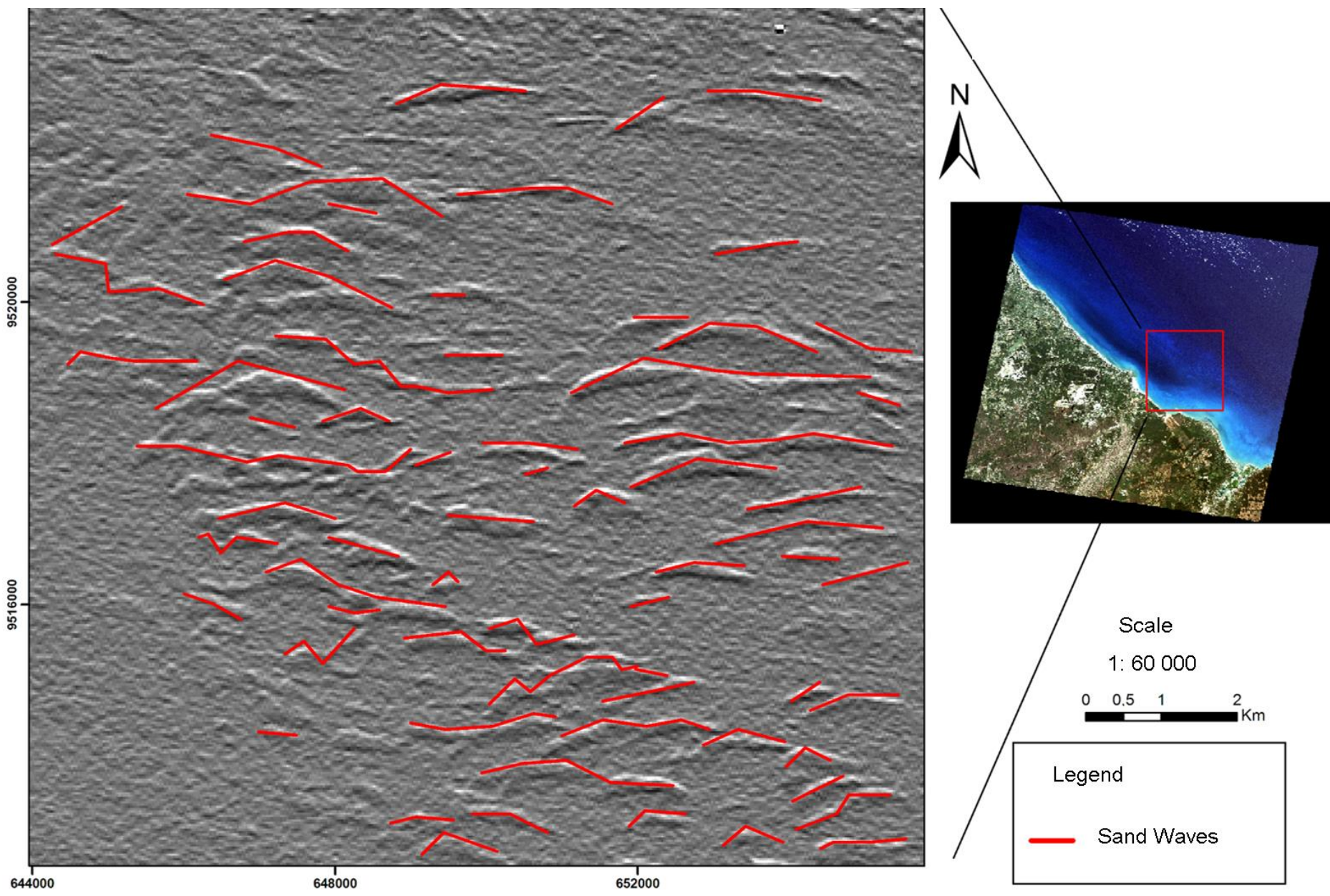

Fig. 7. Sand waves identified on the Study Area, based on a Landsat 5-TM image, band 1, treated with a $90^{\circ}$ directional filter. 


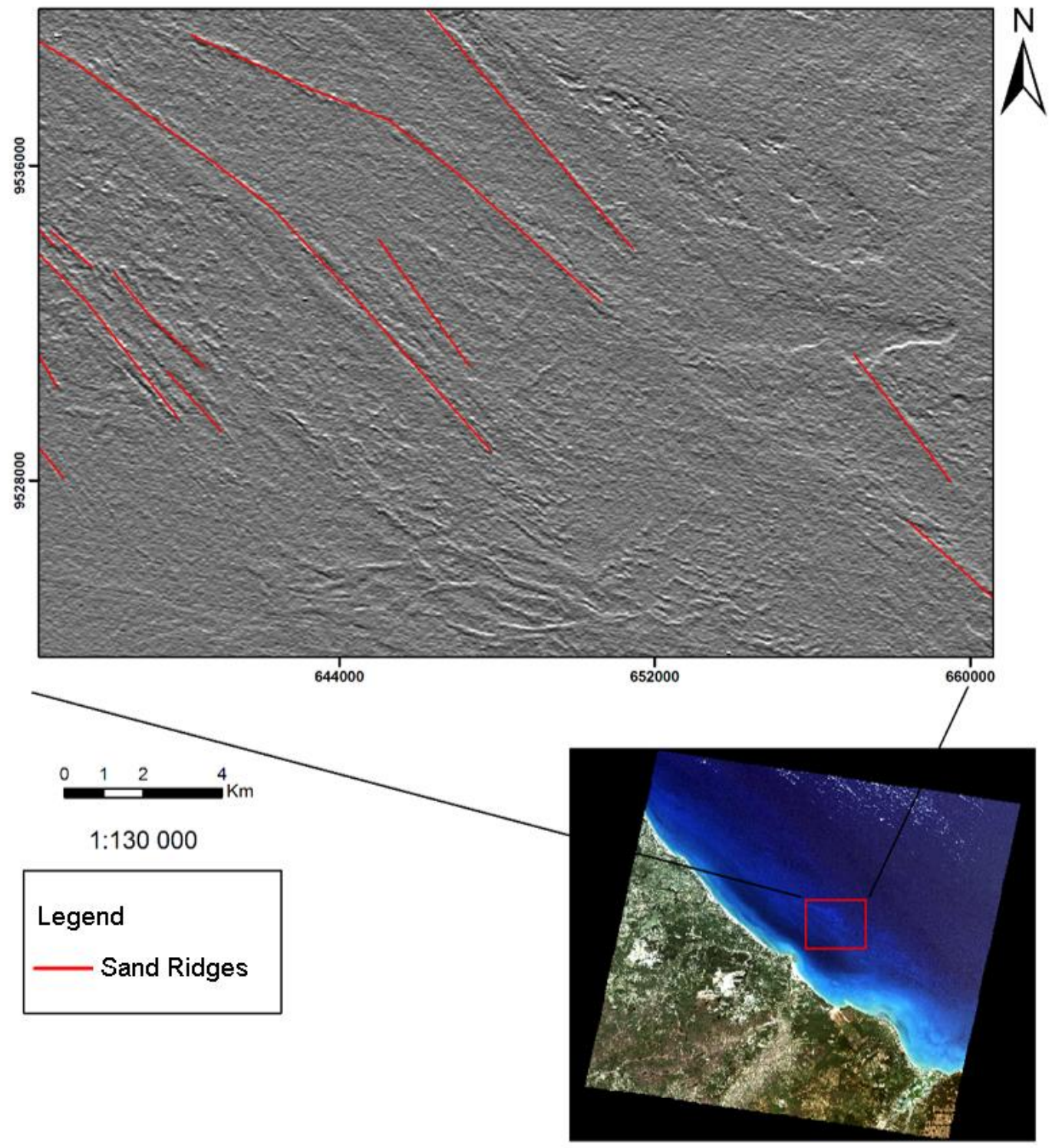

Fig. 8. Sand ridges (longitudinal undulations) identified in the Study Area based on the image of the Landsat 5-TM satellite, band 1, treated with a $90^{\circ}$ directional filter.

The sand ridges with the preferred NW-SE trend are undulations longitudinal to the coastline and, morphologically, can be classified as longitudinal, oblique dunes. Monteiro (2011) performed bathymetric studies and mapped the area from optical sensing images, corroborating the existence of these features.

\section{Conclusion}

The results obtained from the 5-TM Landsat satellite images showed that digitally processed optical images, in the visible region, are an important tool for characterizing and mapping submerged features in places with good transparency and appropriate shallow water depth, which was the case of the studied area.

These results indicate that the optical remote sensing can greatly contribute to determine the seafloor features, which up to now, were only possible with diving and bathymetry techniques.

Recently launched modern sensors tend to expand this application further since they operate in the highest frequency bands of the electromagnetic spectrum. 


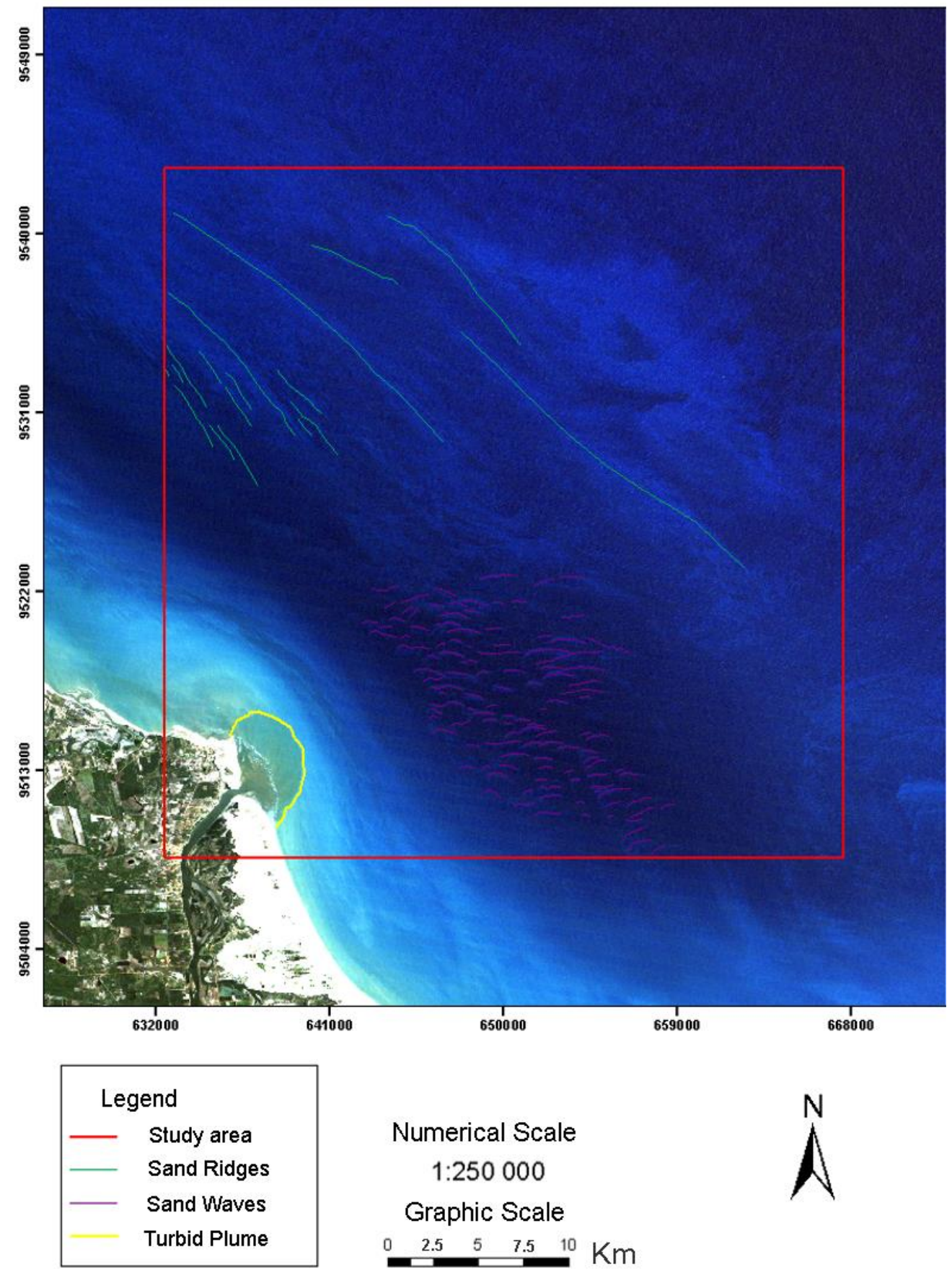

Fig. 9. Morphostructural map of the submerged features interpreted from the processed images.

The submerged features observed in the area have been evidenced in previous processing studies. Some of them are already described in the scientific literature, but not so thoroughly. The use of Landsat images is also advantageous since the INPE (National Institute for Space Research,
Brazil) and the USGS (US Geological Survey, USA) have a free of charge distribution policy of the Landsat satellite images through their portals on the internet, providing high-quality material for research and educational use. 


\section{References}

Andréfouët, S., Riegl, B., 2004. Remote sensing: a key tool for interdisciplinary assessment of coral reef processes. Coral Reefs 23 (1), 1-4. doi. 10.1007/s00338-003-0360-z

Araújo, P.V.N., Amaral, R.F., 2016. Mapping of coral reefs in the continental shelf of Brazilian Northeast through remote sensing. Journal of Integrated Coastal Zone Management 16 (1), 5-20. doi. 10.5894/rgci629

Chaves, P.S., Sides, S.C., Anderson, J.A., 1991. Comparison of three difference methods to merge multi resolution and multispectral data: Landsat TM and SPOT panchromatic. Photogrammetric Engineering and Remote Sensing 57 (3), 295-303.

Crosta, A.P., 1993. Processamento digital de imagens de sensoriamento remoto, Editora Unicamp, Campinas.

Epiphanio, J.C.N., Formaggio, A.R., Santos, A.R., Rudorff, B.F.T., Almeida, C.M., Galvão, L.S. (eds), 2009. Sensoriamento remoto do ambiente: uma perspectiva em recursos terrestres, Editora Parêntese, São José dos Campos.

Gao, J., 2009. Bathymetric mapping by means of remote sensing: methods, accuracy and limitations. Progress in Physical Geography 33(1), 103-116. doi. 10.1177/0309133309105657

Gonzalez, R.C., Woods, R.E. (eds), 1992. Digital image processing, Addison-Wesley, Ney York.

Hamel, M.A., Andréfouët, S., 2010. Using very high resolution remote sensing for the management of coral reef fisheries: Review and perspectives. Marine Pollution

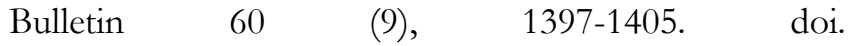
10.1016/j.marpolbul.2010.07.002

Jensen, J.R., 1986. Introductory Digital Image Processing: A Remote Sensing Perspective. Prentice-Hall. New Jersey.

Jolliffe, I.T., 2002. Principal Component Analysis. 2nd Edition. Springer, New York.

Liu, Y., Islam, M.A., Gao, J., 2003. Quantification of shallow water quality parameters by means of remote sensing Progress in Physical Geography 27, 24-43. doi.10.1191/0309133303pp357ra

Mather, P.M., 1999. Computer Processing of RemotelySensed Images, John Wiley \& Sons, West Sussex.
Monteiro, L.H.U., Maia, L.P., 2010. Uso de veículos remotos no estudo do fundo do mar: A nova ciência marinha. Ciência Hoje 46 (272), 38-43.

Monteiro, L.H.U., 2011. Feições superficiais da plataforma continental cearense entre o litoral de Fortaleza e Icapuí. $\mathrm{PhD}$ thesis (Doutorado em Geociências), Universidade Federal de Pernambuco, Recife. Unpublished results.

Oliveira, P.R.A., 2009. Caracterização morfológica e sedimentológica da Plataforma Continental Brasileira adjacente aos municípios de Fortim, Aracati e Icapuí, CE, $\mathrm{MsD}$ thesis (Mestrado em Geodinâmica e Geofísica) Universidade Federal do Rio Grande do Norte, Natal. Unpublished results.

Ongsomwang, S., 2007. Fundamental of Remote Sensing and Digital Image Processing. Digital Image Analysis and Interpretation Textbook Course. School of Remote Sensing, Suranaree University of Technology. Nakhon Ratchasima.

Tabosa, W.F., Amaro, V.E., Vidal, H., 2007. Análise do ambiente costeiro e marinho, a partir de produtos de sensoriamento remoto na região de São Bento do Norte, NE Brasil. Revista Brasileira de Geofísica 25 (Supl.1), 3748.

Tabosa, W. F., Vital, H., 2006. Hydrodynamics forces and environmental impacts on the coast and shelf adjacent to São Bento do Norte, NE Brazil. WIT Transactions on Ecology and Environment 88, 165-174.

Testa, V., Bosence, D.W.J., 1999. Physical and Biological controls on the formation of carbonate and siliclastic bedforms on the north-east Brazilian shelf. Sedimentology 46(2), 279-302. doi: 10.1046/j.13653091.1999.00213.x

Vianna, M.L. Solewicz R., 1988. Feições fisiográficas submarinas da plataforma continental do $\mathrm{RN}$ visíveis por imagens de satélite. V Simpósio Brasileiro de Sensoriamento Remoto, Natal, 581-587.

Vianna, M. L., Solewicz, R., Cabral, A. P., 1991. Sandstream on the Northeast Brazilian Shelf. Continental Shelf Research 11(6), 509-524. 